\title{
FORMAÇÃO DO PROFESSOR DE EDUCAÇÃO INFANTIL NO CURSO DE PEDAGOGIA: REFLEXÕES A PARTIR DA ANÁLISE DAS PRODUÇÕES CIENTÍFICAS (2002-2013)
}

\author{
Daniele Ramos de OLIVEIRA ${ }^{1}$ \\ Rosângela Aparecida Galdi da SILVA ${ }^{2}$ \\ Célia Maria GUIMARÃES ${ }^{3}$
}

RESUMO: Este artigo discute o tema da formação de professores para educação infantil e sintetiza as tendências das teses e dissertações brasileiras sobre essa formação, no âmbito do Curso de Pedagogia. Com essa intenção, contextualizamos de forma breve o histórico da formação dos profissionais de educação infantil, para identificar quais questões são desafiadoras. O mapeamento bibliográfico das pesquisas acadêmicas brasileiras que focalizam a formação inicial de professores para Educação Infantil, no Curso de Pedagogia, publicadas entre 2002 e 2013, foi realizado no banco de dados da Biblioteca Brasileira Digital de Teses e Dissertações (BDTD). Esse levantamento revelou aspectos capazes de se constituir como contribuições às políticas públicas e aos formadores dos professores de educação infantil. A análise apontou o aligeiramento e a precarização dessa formação. Constatou-se que os estudos apontam que o Curso de Pedagogia não fornece os conhecimentos necessários a fim de que os professores escolham encaminhamentos adequados à educação das crianças pequenas, no desempenho da sua função de cuidar-educar. Da mesma forma, compromete a invenção de uma profissão: a do profissional de Educação Infantil. Tal contexto reclama a urgência de esforços para uma formação integrada à futura prática profissional através de projetos os quais articulem formação inicial e continuada.

PALAVRAS-CHAVE: Educação infantil. Políticas públicas. Curso de Pedagogia. Formação. Supervisão.

\section{Introdução}

O propósito deste artigo consiste em discutir as tendências das pesquisas brasileiras, no que tange a teses e dissertações, sobre a formação de professores para a Educação Infantil, no âmbito do Curso de Pedagogia, de maneira a identificar os conflitos e questões que perpassam essa formação. Para essa discussão, far-se-á uma breve contextualização histórica da formação docente no Brasil, no âmbito do Curso de

\footnotetext{
1 Doutoranda em Educação. UNESP - Universidade Estadual Paulista. Faculdade de Ciências e Tecnologia - Pós-graduação em Educação. Presidente Prudente - SP - Brasil. 19060-900 unespdaniele@gmail.com

2 Doutoranda em Educação. UNESP - Universidade Estadual Paulista. Faculdade de Ciências e Tecnologia - Pós-graduação em Educação. Presidente Prudente - SP - Brasil. 19060-900 rosangela.apgaldi@gmail.com

3 Pós-doutorado. ULISBOA - Universidade de Lisboa. Lisboa - Portugal. 1649-004 e Escola Superior de Educação do Instituto Politécnico de Santarém. Santarém - Portugal. 2001-902. UNESP - Universidade Estadual Paulista. Faculdade de Ciências e Tecnologia. Presidente Prudente - SP - Brasil. 19060-900 cmgui@fct.unesp.br
} 
Pedagogia, a fim de que se possa, na sequência, iniciar um debate sobre as tendências demonstradas pelas pesquisas acadêmicas encontradas por meio de mapeamento bibliográfico realizado, dentro do período de 2002 a 2013.

Diante disso, o artigo foi organizado em quatro seções, além desta introdução. Na primeira, resgatar-se-á brevemente o histórico da formação para Educação Infantil, bem como seus problemas e necessidades. Na segunda seção, apresentam-se as estratégias metodológicas utilizadas para o mapeamento bibliográfico das pesquisas acadêmicas sobre formação inicial para Educação Infantil, além de um panorama geral dos resultados. A terceira seção, subdividida em itens, abrange uma síntese das dissertações e teses por agrupamentos, de acordo com as temáticas e questões específicas tratadas em cada uma delas. Para finalizar, na quarta seção, são expostas as reflexões com base na análise da produção acadêmica identificada.

\section{O curso de pedagogia e a formação do professor para educação infantil}

Até a reforma educacional, reivindicada pela sociedade e conquistada por meio da Constituição Federal de 1988 (BRASIL, 1988), Lei 8069/90 (BRASIL, 1990) e Lei de Diretrizes e Bases - LDB 9394/96 (BRASIL, 1996), não havia exigência de formação ou qualificação para o trabalho com crianças pequenas, em creches ou pré-escolas. Em consequência, a formação inicial para atuação na Educação Infantil ganha relevância. Nas Diretrizes Curriculares Nacionais para a Educação Infantil, de acordo com o Parecer CNE/CEB 20/2009 (CNE, 2009), esse profissional passa a ser considerado professor. Nesse sentido, a partir da promulgação da LDB 9394/96, os professores desfrutam de direitos garantidos, como o da formação inicial e continuada. Defende-se, assim, que a formação de professores para a Educação Infantil é fundamental, porque se considera que a formação é requisito para que o atendimento infantil institucionalizado ofereça condições e ações de cuidados e educação os quais respeitem os direitos fundamentais das crianças, lembrando a condição de sujeitos de direitos que são. Tal respeito se traduz na atuação profissional ancorada em propostas intencionalmente concebidas nas necessidades e especificidades da infância e da criança.

Não havia, até a década de 1990, a preocupação com a formação para atuar na Educação Infantil. Havia, de fato, algumas reformas, de iniciativa das próprias universidades e da formação em cursos de nível médio. Somente em 1994, com o documento Por uma política de formação do Profissional de Educação Infantil 
(BRASIL, 1994), o MEC forneceu subsídios, princípios e diretrizes para a política educacional, inclusive para a formação dos profissionais da Educação Infantil. Esse documento representou uma tomada de posição política.

Fica patente, portanto, que a LDB 9394/96 explicitou a necessidade de formação de docentes para a Educação Infantil, rompendo com os resquícios da história da Educação Infantil, a qual não exigia profissionais formados para a educação das crianças pequenas. Em compensação, a mesma Lei criou os ISE - Institutos Superiores de Educação - no que se refere aos cursos e aos programas de formação, atribuindolhes, dentre outras, a formação para a Educação Infantil e para as primeiras séries do Ensino Fundamental, por meio do Curso Normal Superior, o qual equivalia à formação oferecida no Curso de Pedagogia. Na verdade, para Saviani (2005), foi inventada uma nova figura institucional concorrente do Curso de Pedagogia, podendo fazer tudo o que estes fazem, porém, de forma mais aligeirada, mais barata, com cursos de curta duração.

Apesar de a formação dos professores, desde a LDB 9394/96, ter primado por uma formação no Ensino Superior para a docência na primeira Etapa da Educação Básica, também foi admitida como formação mínima, de nível médio, a modalidade normal. Mesmo em um ambiente confuso de definição, o Curso de Pedagogia, na década de 90, tornou-se a principal fonte de formação para atuação na Educação Infantil e nos anos iniciais do Ensino Fundamental.

Seguindo a tradição dos cursos de magistério de nível médio, os atuais cursos de Pedagogia costumam preparar concomitantemente o professor para atuar na Educação Infantil e nos iniciais do Ensino Fundamental, conforme prevê o Parecer CNE/CP 05/2005 (CNE, 2005), o qual fixa as Diretrizes Curriculares Nacionais para o Curso de Pedagogia, abarcando histórico, finalidade, princípios curriculares, objetivos, perfil do licenciado, organização, duração dos estudos e estágio curricular do referido curso. A suspeita é que, entendida, como em tempos passados, mais como uma contemplação da formação do professor dos primeiros anos do Ensino Fundamental, a formação oferecida não considere devidamente as especificidades da educação das crianças na pré-escola e nas creches (GATTI; BARRETO, 2009).

A Resolução CNE/CP 1/2006 instituiu as novas Diretrizes Curriculares Nacionais para o Curso de Graduação em Pedagogia, licenciatura, abrangendo a formação de professores para a Educação Infantil e anos iniciais do Ensino Fundamental, para o ensino médio, na modalidade Normal e para a Educação de Jovens e Adultos, Educação Profissional, além da formação de gestores (CNE, 2006). Essa 
resolução definiu princípios, condições de ensino e de aprendizagem, procedimentos para planejamento e avaliação. Libâneo (2006, p.844) considera que "[...] a resolução trata, portanto, da regulamentação do Curso de Pedagogia exclusivamente para formar professores para a docência naqueles níveis do sistema de ensino.” Logo, não havia preocupação com a formação dos especialistas em educação, os quais eram formados pelo Curso de Pedagogia. Dessa forma, identifica-se que o foco do Curso de Pedagogia é a docência, conforme consta no parágrafo $1^{\circ}$. do artigo $2^{\circ}$ da Resolução $\mathrm{CNE} / \mathrm{CP}$ 1/2006, com a seguinte definição para docência:

[...] ação educativa e processo pedagógico metódico e intencional, construído em relações sociais, étnico-raciais e produtivas, as quais influenciam conceitos, princípios e objetivos da pedagogia, desenvolvendo-se na articulação entre conhecimentos científicos e culturais, valores éticos e estéticos inerentes a processos de aprendizagem, de socialização e de construção do conhecimento, no âmbito do diálogo entre diferentes visões de mundo. (CNE, 2006, p.1).

O artigo 10 da Resolução CNE/CP 1/2006 deliberou em regime de extinção as Habilitações nos cursos de Pedagogia, como Educação Infantil ou anos iniciais do Ensino Fundamental, mas sugeriu que os aprofundamentos necessários estivessem contemplados no projeto pedagógico de cada curso, sem mencionar quais são as áreas de atuação. Com isso, o Conselho Nacional de Educação simplesmente ignorou experiências que vinham contribuindo, durante anos, com a formação de professores para a Educação Infantil e para os anos iniciais do Ensino Fundamental.

Como resultado das Novas Diretrizes Curriculares para o Curso de Pedagogia, os cursos remanescentes foram reorganizados, com o objetivo de atender à legislação em vigor. Algumas alterações ocorreram na prática, como a extinção das habilitações, a base de formação na docência e ainda a adequação para uma formação abrangente. Essa legislação impõe ao Curso de Pedagogia uma distorção quanto ao entendimento de docência e pedagogia, o que cooperou para a eliminação da formação do especialista, ou seja, profissionais da educação para Administração, Planejamento, Inspeção, Supervisão e Orientação Educacional. Além disso, extinguiu as habilitações e atribuiu ainda ao curso a incumbência de formar o professor para as tarefas de pesquisa e gestão, o que demonstra problemas nos conceitos das atividades envolvendo essas atribuições, tendo em vista que ser professor é diferente de ser gestor. 
Diante da explicação, admite-se que as decisões tomadas na área das políticas públicas, como a Resolução $\mathrm{CNE} / \mathrm{CP}$ 1/2006, podem colocar em risco o estabelecimento da profissionalidade docente, no que refere à Educação Infantil, uma vez que não ajuda na formação dos profissionais dessa etapa. Com essa hipótese, foi desenvolvido um mapeamento bibliográfico, a ser descrito nos próximos itens.

\section{Caminhos da pesquisa}

Procedeu-se a um mapeamento bibliográfico das pesquisas acadêmicas brasileiras publicadas entre 2002 e 2013, vinculadas aos Programas de Pós-Graduação em Educação que focalizam a formação inicial de professores para Educação Infantil, desenvolvida no Curso de Pedagogia, com o intuito de identificar sua contribuição para essa formação. O marco inicial do período escolhido para mapeamento das produções ocorreu em função da aprovação pelo Conselho Nacional de Educação da Resolução CNE/CP 01/2002 (CNE, 2002), a qual estabelece as Diretrizes Curriculares Nacionais para a formação de professores da Educação Básica, em nível superior, curso de licenciatura, de graduação plena. As dissertações de mestrado e teses de doutorado foram escolhidas, como corpus do estudo, por ser a Pós-Graduação um lugar privilegiado da produção de conhecimento, em torno da qual se articulam diferentes pesquisadores para desenvolver projetos de interesse social, por um período relativamente extenso, com rigor científico e aprofundamento teórico, o que pode sugerir a garantia de sua credibilidade.

O mapeamento bibliográfico foi realizado no banco de dados na Biblioteca Brasileira Digital de Teses e Dissertações (BDTD) ${ }^{4}$, com base nos seguintes descritores: “formação inicial/Educação Infantil" e "Pedagogia/Educação Infantil”. O critério principal de seleção foram os objetivos e/ou resultados dos estudos que deveriam discutir a formação inicial de professores para Educação Infantil, no âmbito do Ensino Superior. Outro critério adotado para composição da amostragem foi o de que os estudos estivessem disponíveis em websites e vinculados a Programas de PósGraduação em Educação. Este último procedimento se justifica pelo fato de esses estudos poderem utilizar outros referenciais teóricos, pouco comuns na educação, o que poderia desencadear uma análise ainda mais complexa que aquela prevista para os limites deste texto.

\footnotetext{
${ }^{4}$ Como a Universidade Estadual Paulista não se inclui na BDTD, optou-se por buscar pesquisas nos diferentes câmpus com Programas de Pós-Graduação em Educação dessa universidade, uma vez que se considera ser uma das principais produtoras de pesquisas acadêmicas do país.
} 
No período entre 2002 e 2013, foram selecionadas 13 pesquisas acadêmicas que se adequavam aos critérios mencionados, sendo 11 dissertações e 2 teses. A quantidade de estudos localizados a partir dos indicadores citados, porém, foi bem maior, uma vez que os sistemas de busca da BDTD costumam localizar todas as pesquisas que contêm, nos resumos, títulos e/ou palavras-chaves os termos utilizados. A título de exemplo, somente com o uso dos indicadores "formação inicial/Educação Infantil" foram localizados, na BDTD, 100 documentos. Uma segunda etapa consistiu, portanto, na seleção de quais estudos comporiam a amostragem e o corpus do estudo, com base nos critérios já abordados.

Após o processo de localização, foi feita a leitura dos resumos e considerações finais dos textos de pesquisa, cujo conteúdo possibilitou as classificações preliminares. $\mathrm{Na}$ sequência, foram identificados os temas abordados e os principais resultados. Alguns estudos, dos quais o resumo não permitia compreender claramente todos os aspectos necessários para sistematização desejada, foram lidos na íntegra. Em consequência a esses procedimentos, foi desenvolvida a discussão apresentada nos próximos itens.

Os estudos sobre formação de professores para educação infantil no curso de pedagogia

As pesquisas sobre a formação inicial de professores para Educação Infantil, no que concerne às práticas formativas, no âmbito do Curso de Pedagogia, foram distribuídas por ano de publicação, conforme consta no Quadro 1.

Quadro 1 - Distribuição de dissertações e teses publicadas de 2002 a 2013, sobre formação inicial de professores para Educação Infantil no Curso de Pedagogia, em Programas de Pós-Graduação em Educação, segundo o ano de publicação.

\begin{tabular}{|c|c|c|c|c|c|c|c|c|c|c|c|c|}
\hline $\begin{array}{c}\text { Ano de } \\
\text { publicação }\end{array}$ & 2002 & 2003 & 2004 & 2005 & 2006 & 2007 & 2008 & 2009 & 2010 & 2011 & 2012 & 2013 \\
\hline $\begin{array}{c}\text { Total de } \\
\text { teses e } \\
\text { dissertações }\end{array}$ & 1 & 2 & - & 1 & 1 & 3 & - & 2 & 2 & 1 & - & - \\
\hline
\end{tabular}

Fonte: Elaboração própria.

Não foram localizadas dissertações e teses disponibilizadas em meio digital sobre formação inicial de professores para Educação Infantil, nos anos de 2004, 2008, 2012 e 2013. É possível, contudo, considerar a hipótese de haver estudos defendidos em 
2013 e não identificados, até o momento do levantamento bibliográfico ${ }^{5}$, devido à atualização da BDTD em relação ao ano referido. Os anos de 2003, 2007, 2009 e 2010 foram os mais expressivos, em termos de quantidade de publicações. Esse ligeiro aumento pode relacionar-se à publicação da Resolução CNE/CP 1/2006, que instituiu as Novas Diretrizes Curriculares Nacionais para o Curso de Graduação em Pedagogia, tornando a docência para Educação Infantil e anos iniciais do Ensino Fundamental a base dessa formação.

O processo de análise dos dados obtidos possibilitou apontar algumas tendências presentes nas pesquisas selecionadas. Nas seções que se seguem, serão demonstrados os múltiplos enfoques e perspectivas encontrados, distribuídos nas seguintes dimensões: "O papel da formação inicial na prática educativa dos professores"; "O olhar dos discentes sobre sua formação para a Educação Infantil"; "Formação para a Educação Infantil no Curso de Pedagogia"; "Debates políticos e estudos de cunho bibliográfico".

\section{O papel da formação inicial na prática educativa dos professores}

Quatro estudos (SILVA, J., 2002; DALRI, 2007; IRGANG, 2009; OSHIRO, 2010) investigaram o papel da formação inicial na prática educativa dos professores de Educação Infantil, de modo a analisar as contribuições e/ou implicações dessa formação para a ação docente, sendo que um deles buscou conhecer especificamente o lugar da infância na formação inicial das professoras. Tanto Jória Pessoa de Oliveira Silva (2002) quanto Oshiro (2010) desenvolveram seus estudos em Campo Grande-MS. Jória Silva (2002) verificou que a formação inicial, no Curso de Pedagogia, apesar de receber muitas críticas, tem propiciado aos professores reflexões sobre as concepções de Educação Infantil, infância, entre outras. Entretanto, para a mesma autora, a formação profissional a que os professores têm tido acesso resulta em profissionais que executam tarefas, o que não corresponde ao perfil desejado e necessário para sociedade atual.

Considerando que todos os sujeitos da pesquisa de Oshiro (2010) eram professoras, que, ao ingressarem no Curso de Pedagogia, já tinham noções de prática e teoria, por terem se formado primeiramente no Magistério de Nível Médio, a autora salienta que a qualidade do trabalho educativo desenvolvido por esse grupo pode ser resultado de formação consistente realizada simultaneamente ao trabalho na sala de aula. Nas palavras da autora: “[...] ter cursado Pedagogia e trabalhado ao mesmo tempo

${ }^{5}$ O levantamento bibliográfico foi realizado em novembro e dezembro de 2013. 
constituiu um processo de formação que criou condições de articulação entre teoria e prática.” (OSHIRO, 2010, p.126).

Diante dessa constatação, a autora enfatiza a necessidade de um sistema amplo de formação, o qual garanta ampliação do universo cultural e a compreensão dos professores a respeito da infância e do papel da Educação Infantil; a urgência de que o curso de formação tenha uma estrutura curricular que integre os fundamentos e a prática de trabalho em sala de aula, além de destacar que a formação para atuar com criança pequena deve se dar no Curso de Pedagogia, em âmbito de Ensino Superior, porém, de um modo que o curso abranja as peculiaridades da infância. Para Oshiro (2010), a mistura da formação do professor que trabalhará nos anos iniciais do Ensino Fundamental com a formação do educador infantil pode acabar contaminando a última, com a disciplinarização dos conteúdos e o esvaziamento do espaço lúdico. Assim, conforme a autora, é preciso garantir que a Educação Infantil não seja apenas um rol de disciplinas do Curso de Pedagogia, mas o seu eixo.

Dalri (2007), que estudou especificamente formação docente inicial para a ação docente com crianças de zero a três anos, constatou, por meio de entrevistas com professoras egressas, a baixa capacidade do curso para trabalhar com essa faixa etária, uma vez que os conteúdos costumam ser mais direcionados para o trabalho com crianças de pré-escola e anos iniciais do Ensino Fundamental. No Curso de Pedagogia, as professoras afirmaram ter conhecido muito pouco sobre o desenvolvimento da criança de zero a três anos. Nesse sentido, a autora indica a revisão e a reformulação dos currículos de formação inicial das professoras da Educação Infantil, a fim de que possam assegurar conhecimentos e competências profissionais para um trabalho de mais qualidade com a criança de zero a três anos. Dalri (2007) aponta ainda a ausência de articulação entre teoria e prática, num curso de Pedagogia em que se apresentam inicialmente os fundamentos da Educação, depois as metodologias e, por último, um estágio que supõe a aplicação pelos alunos dos conhecimentos adquiridos ao longo do curso. Do ponto de vista da pesquisadora, para viabilizar uma formação que integre teoria à prática, é preciso criar parceria com algumas escolas, garantindo discussões e condução do projeto pedagógico da instituição que ofereça espaço para realização do estágio, num tipo de vínculo capaz de proporcionar resultados tanto à instituição formadora quanto à escola.

Irgang (2009) teve como objetivo conhecer e analisar os saberes e as significações imaginárias de três professoras de Educação Infantil, egressas do Curso de 
Pedagogia, da Universidade Federal de Santa Maria, acerca do lugar da infância na formação inicial e na experiência profissional. As professoras investigadas mencionaram a existência do debate sobre infância e criança, nas disciplinas do curso, todavia, alertaram que a infância da criança de zero a três anos ainda precisa ser contemplada. Cabe mencionar as contribuições para o Curso de Pedagogia, na especificidade da Educação Infantil, aludidas nas narrativas das professoras:

[...] as experiências interdisciplinares promovidas no curso, as observações crítico-reflexivas acompanhadas pelos professores formadores, as discussões e as alternativas que podem ser construídas na disciplina articuladora (PED), bem como a aproximação entre escola-universidade, a fim de conhecer a realidade e os contextos em que se encontram as crianças na Educação Infantil e suas infâncias. (IRGANG, 2009, p.120).

\section{O olhar dos discentes sobre sua formação para educação infantil}

Outras duas pesquisas (SILVEIRA, 2007; FEBRONIO, 2010) sobre a formação inicial de professores para Educação Infantil enfocaram o ponto de vista dos discentes do Curso de Pedagogia. Silveira (2007) e Febronio (2010) tiveram como objetivo, em suas dissertações de mestrado, investigar o lugar ou as contribuições do Curso de Pedagogia para a formação de professores da Educação Infantil sob a ótica dos alunos.

Febronio (2010) concluiu que a formação de professores de Educação Infantil se encontra em definição nos cursos de Pedagogia, sendo que as universidades têm apresentado a preocupação de rever suas propostas curriculares nesse sentido. Para a autora, a contribuição do Curso de Pedagogia para a formação de professores de Educação Infantil ainda é parcial e restrita, devido aos seguintes fatores: “[...] propostas tímidas em relação ao currículo, estágios pouco planejados, o que dificulta a articulação da teoria com a prática, e a indefinição da identidade do curso.” (FEBRONIO, 2010, p.13). As alunas investigadas nos cursos de Pedagogia consideram que o curso não as habilita a ensinar, o que, na visão da autora, demonstra uma visão restrita da prática ou técnica, num modelo chamado "racionalidade técnica" ou "educação bancária". Para a pesquisadora, o ideal seria pensar em um curso fundamentado no modelo de "racionalidade crítica", o qual coloca os alunos no centro do processo, percebidos como agentes na construção do seu saber. O estudo ainda evidenciou como fundamental, no Curso de Pedagogia, um currículo coletivamente negociado em sala de aula entre 
alunos, docentes, coordenação e direção. O estágio foi outro ponto abordado que requer revisão, para que não seja mais compreendido como aplicação da teoria, mas como um “[...] lugar em que, com a imersão do aluno, se produz teoria, portanto, lócus de conhecimento e de pesquisa." (FEBRONIO, 2010, p.15).

A formação para Educação Infantil ainda ocupa um lugar marginal, de acordo com Silveira (2007). Segundo essa autora, é necessário repensar a estrutura curricular, de maneira a garantir um Curso de Pedagogia que propicie a formação do profissional que atue em todos os campos da educação. Nesse sentido, a pesquisadora opõe-se à defesa de um Curso de Pedagogia que forme exclusivamente para a Educação Infantil. Evidencia ainda que a formação proposta pelo MEC indica um aligeiramento, coadunado aos princípios neoliberais que ganharam força no Brasil, na década de 1990. Além disso, a autora destaca a necessidade de ouvir mais os estudantes, os quais podem apresentar seus olhares sobre o currículo do curso em movimento, de sorte a detectar o que pode ser mantido ou superado. Em seus dados, como Febronio (2010), registrou que, para os alunos, as disciplinas não revelam a relação teoria e prática e o estágio se apresenta como um espaço que possibilita contato e conhecimento das realidades, concepções e práticas educativas nas instituições de Educação Infantil. No entanto, o tempo destinado a ele é percebido como curto para garantir vivência e elaboração de propostas de superação das situações percebidas.

\section{Formação para educação infantil no curso de pedagogia}

As investigações de Anamaria Santana da Silva (2003), Costa (2005) e Oliveira (2007) buscaram averiguar a formação de professores para a Educação Infantil do Curso de Pedagogia.

Costa (2005) teve como objetivo, através da análise curricular, investigar a formação em seus pressupostos teórico-práticos, e seus resultados mostraram aspectos relevantes tanto nas áreas prática (estágio) quanto teórica (referenciais e embasamento teórico). A despeito disso, considera que há muitas mudanças necessárias para uma proposta mais abrangente para a formação do professor da Educação Infantil que integre a qualificação em Educação Infantil com a formação geral.

Oliveira (2007), por sua vez, avaliou como o Curso de Pedagogia tem contribuído na formação para a docência na Educação Infantil. Considerou, com base em seus dados, que o projeto do Curso de Pedagogia não favorece as condições de formação necessárias para a construção do sentido de docência na Educação Infantil, na 
perspectiva da organização do trabalho pedagógico e da gestão educacional. Este se restringe ao estudo de conteúdos da escola prescritos pelo currículo oficial do Ensino Fundamental, cuja ênfase está no ensino da leitura e da escrita. As disciplinas de metodologias do curso investigado por Oliveira (2007) são o espaço de definição do conteúdo de formação para docência na Educação Infantil, e o estágio é percebido como vitrine e ponto de chegada das aprendizagens dos licenciados.

Anamaria Santana da Silva (2003) discutiu, em sua tese, a formação universitária para professores de Educação Infantil e demonstrou que os cursos de Pedagogia oferecidos em algumas universidades federais eram deficientes, porque apresentavam ausência de formação específica àqueles que desejassem atuar nesse nível da Educação Básica. A autora também aponta que a prioridade dessa formação está na pré-escola; a criança e a infância ocupam espaço restrito nas discussões, no decorrer dos cinco cursos de Pedagogia de universidades federais investigados, identificando a presença incipiente de uma Pedagogia da Educação Infantil, embora haja predominância do modelo escolar do Ensino Fundamental.

\section{Debates políticos}

Foram agrupados, numa nova dimensão, três estudos (RODRIGUES, 2003; CHRUN, 2009; ALMADA, 2011) que envolviam aspectos políticos na investigação sobre formação inicial no Curso de Pedagogia para formação de professores de Educação Infantil. Almada (2011), em sua tese, analisou as implicações decorrentes das políticas educacionais nos processos de apropriação e objetivação, concernentes à formação do professor para a Educação Infantil, no Curso de Pedagogia. Investigou, além disso, as possibilidades fornecidas pela Teoria Histórico-Cultural para o enfrentamento da alienação imposta à atividade docente por essas políticas. A análise dos dados possibilitou à autora constatar que o ideal de formação preconizado pelo capital se faz presente no projeto do curso estudado, através das concepções teóricas do aprender a aprender e da teoria da reflexividade. Como resultado dessa adoção, a vida cotidiana se manifesta na maioria das ações executadas por discentes e docentes, sendo que os conceitos se caracterizam pela ausência de percepção consciente de suas reais intenções e, por conseguinte, por uma prática educativa distante da ciência, da arte e da filosofia. Nessa perspectiva, como a formação de professores não fornece os conhecimentos necessários, essa falta repercutirá na prática pedagógica com encaminhamentos parecidos com o Ensino Fundamental. Os resultados dessa pesquisa 
"[...] apontam para a importância e necessidade de os educadores, principalmente os que trabalham com a formação para a educação básica, apoiarem sua ação em uma teoria que fundamente a educação desenvolvente, como é o caso da Teoria HistóricoCultural." (ALMADA, 2011, p.6).

Chrun (2009) teve como objetivo principal reconstituir a trajetória de formação do professor paranaense, por meio do estudo das políticas e da legislação educacionais implementadas entre 1961 e 1996. A autora considera, com base em seus dados, que o estado do Paraná sempre galgou grandes propostas para formação do professor, inclusive de Educação Infantil. Pontua, em sua dissertação, alguns momentos específicos da história, de modo a comprovar sua conclusão e a ressaltar as mudanças de paradigmas os quais rompam com a racionalidade técnica, com vistas à formação de professores críticos e reflexivos, enriquecida por olhares teóricos mais adequados à condição da criança como ser histórico e social.

Rodrigues (2003) faz uma análise filosófica, de linha materialista histórica, sobre as novas regulamentações propostas para a formação dos professores, em especial o professor de Educação Infantil, após a promulgação da LDB 9394/1996. Para a autora, o modelo que está sendo proposto para formação de professores, pelo governo, apresenta uma “[...] supervalorização da prática, em detrimento da formação teórica, sem a qual não é possível realizar uma reflexão qualitativa. Seu projeto está imbuído de conteúdo ideológico, legitimador da fragmentação do conhecimento.” (RODRIGUES, 2003, p.114). Nessa perspectiva, enfatiza uma contradição que impera no fato de que, ao mesmo tempo em que o ato educativo se torna mais complexo, na conjuntura atual, a formação de professores tem suas metas e objetivos reduzidos. A partir dessas constatações, Rodrigues (2003) sublinha a necessidade de uma formação baseada na concepção omnilateral da formação humana, numa perspectiva transformadora, em que todas as dimensões a serem desenvolvidas estejam presentes, como o conhecimento histórico-científico, ético-político e estético. Propõe a construção de uma identidade profissional unitária, que tenha por base "[...] a docência, mantendo a articulação entre formação inicial e continuada, a relação do ensino e pesquisa, conteúdo específico e conteúdo pedagógico, de maneira a atender à natureza e à especificidade do trabalho pedagógico, que efetive o ditame da práxis.” (RODRIGUES, 2003, p.119).

\section{Estudos de cunho bibliográfico}


Por fim, foram localizados dois estudos (VOLPI, 2006; SILVA, R., 2011) de cunho bibliográfico. No estudo de Volpi (2006) se desenvolve um estado da arte de teses e dissertações que têm por tema a Educação Infantil, defendidas nos Programas de Pós-Graduação em Educação nas Instituições Superiores do Estado do Paraná, no período de 1997 a 2004, com o objetivo de mapear os temas abordados, os avanços e as perspectivas na direção da educação da criança para a emancipação como sujeito social e as proposições para a formação de professores. A autora entende, com base na análise de 1 tese e 11 dissertações, que a melhoria da formação de professores para a Educação Infantil constitui um desafio neste momento em que se aspira a mudanças de comportamento, de atitudes e de formas, no educar e cuidar da criança pequena.

Já Rosangela Aparecida Galdi da Silva (2011) pesquisa a problemática da formação inicial do professor de Educação Infantil no Curso de Pedagogia da Faculdade de Ciências e Tecnologia - UNESP de Presidente Prudente/SP. Nesse trabalho, identifica avanços, impactos e desafios postos aos profissionais da Educação Infantil, assim como as políticas públicas voltadas para infância. Caracteriza limitações impostas aos cursos de Pedagogia pela Resolução CNE/CP 1/06, a partir da análise das mudanças ocorridas no processo de formação inicial para a constituição da docência na Educação Infantil. A autora, através do mapeamento de dissertações e teses dos Programas de PósGraduação em Educação reconhecidos pela Capes e das experiências da Itália, Suécia e Portugal, revela as necessidades formativas dos profissionais que trabalham com crianças pequenas e, por consequência, indica pressupostos para iluminar uma discussão curricular no que se refere à formação dos professores de Educação Infantil. Propõe a realização de projetos de formação e de supervisão entre instituições de Educação Infantil e universidades, que levem em conta as necessidades formativas e, baseados nos pressupostos indicados, priorizem o cuidar-educar as crianças pequenas, as instituições de Educação Infantil, o trabalho docente e a formação dos professores.

\section{Diante de tudo o que foi exposto ...}

A inclusão da Educação Infantil, abrangendo o atendimento em creches e préescolas, como primeira etapa da Educação Básica, desde a LDB 9.394/96, representou uma mudança radical na compreensão do atendimento à infância, o qual passou a ser caracterizado como educacional, devendo, portanto, seguir as diretrizes e normas da educação. No entanto, a Educação Infantil teve sua gênese sob o signo da assistência e assim se manteve, por longo período. Desenvolveu-se de forma periférica ao sistema 
escolar, como lugar de guarda, ou mesmo relegada à informalidade, à filantropia, ao voluntariado e a arranjos domésticos. Essa experiência marcou profundamente essa etapa, hoje integrante da Educação Básica, imprimindo determinadas identidades a esse trabalho, que ainda perduram.

A Educação Infantil sofre de indefinição em relação a importantes aspectos de sua organização para o trabalho pedagógico, de seus objetivos e de suas funções políticas, sociais e pedagógicas. O debate é complexo, pressupondo concepções de infância, de criança e de educação que permitem pensar a referida etapa para além do arremedo da forma escolar clássica, como cópia ou prolongamento do Ensino Fundamental, do currículo disciplinar e da educação como ensino e aprendizagem, nos moldes da racionalidade técnica.

As especificidades da Educação Infantil e as necessidades formativas de seus profissionais responsáveis pelo processo educativo estão articuladas ao cuidado e à atenção, acrescidas ainda da informalidade e da imitação do Ensino Fundamental presentes nos arranjos de trabalho nas creches e pré-escolas, fruto do descaso de séculos, aspectos os quais obrigam a revisão dos padrões usuais de formação docente.

Contudo, o conjunto de pesquisas localizadas aponta que, embora os cursos de Pedagogia apresentem a preocupação de rever suas propostas curriculares de modo a contemplar a Educação Infantil, a formação continua restrita e parcial, desenvolvida de um modo que o modelo escolar do Ensino Fundamental consiste no pilar. Além disso, as poucas reflexões e estudos sobre Educação Infantil existentes nos cursos de Pedagogia costumam se restringir à pré-escola, apesar de a infância de zero a três anos integrar a etapa da educação infantil, no Brasil.

Oshiro (2010) se posiciona, ainda que timidamente, a favor de um Curso de Pedagogia voltado especificamente para a Educação Infantil, por compreender que a concomitância com a formação para o Ensino Fundamental contamina a formação, com a disciplinarização dos conteúdos e o esvaziamento do espaço lúdico. Outros (COSTA, 2005; SILVEIRA, 2007) se opõem à defesa de um Curso de Pedagogia que forme exclusivamente para a Educação Infantil, ressaltando a necessidade de mudanças a fim de que se contemple uma proposta mais abrangente de formação capaz de integrar a qualificação para Educação Infantil com a formação geral.

A maioria dos estudos analisados defende um tipo de Curso de Pedagogia que supere uma formação baseada na racionalidade técnica, propicie articulação entre teoria e prática e no qual o estágio não seja mais compreendido como vitrine ou aplicação de 
teoria, mas como um momento de produção de conhecimento, tanto para instituição quanto para as escolas. Todavia, conforme especificam Guimarães et al. (2009, p.2654):

Se pretendemos proporcionar a invenção da profissão, a construção da identidade do professor de crianças pequenas com a clareza dos seus papéis, assim como da instituição incumbida de cuidar-educar os pequenos, precisamos rever os modos de fazer a formação docente.

É preciso, por conseguinte, ponderar sobre a formação de um novo perfil profissional que incorpore as novas concepções sobre a qualidade do atendimento à criança pequena (CAMPOS, 1994), estimulando uma compreensão alargada das funções da instituição de Educação Infantil, ancorada na compreensão do período da infância como um tempo de participação e de produção de cultura e as crianças como capazes de se expressarem por meio de diferentes linguagens.

Entretanto, o aligeiramento e a precariedade da formação para professores de Educação Infantil, no Curso de Pedagogia, provocados pela Resolução CNE/CP 1/2006, que instituiu as Novas Diretrizes Curriculares Nacionais para o Curso de Graduação em Pedagogia, coadunam com a constituição de um curso que não fornece os conhecimentos necessários para que os professores possam propor encaminhamentos adequados às crianças pequenas. Com o Curso de Pedagogia organizado de acordo com a Resolução CNE/CP 1/2006, a qual determinou o fim das Habilitações para Educação Infantil, e com o Magistério em Nível Médio, restou aos professores pouco tempo de estudo para compreenderem como a criança da faixa etária atendida na educação infantil aprende, desenvolve-se e quais são as atitudes e ações específicas que o profissional deveria apresentar frente a ela, de modo a apoiar e acompanhar sua inserção no mundo cultural.

Para alteração dessa situação, é preciso que os processos formativos, inclusive nos cursos de Pedagogia, atendam às especificidades do trabalho com crianças pequenas, em busca da construção de saberes e experiências necessárias ao profissional de Educação Infantil. Desse modo, ressaltamos que essa formação precisa contemplar o cuidar-educar, como função dos professores das instituições de Educação Infantil, que não abrange atividades estanques. Contrariamente, elas precisam estar unificadas para, de fato, conseguir atender às especificidades das crianças dessa faixa etária. Para o professor de educação infantil exercer a função de cuidar e educar historicamente 
conquistada como expectativa da sociedade brasileira, ele necessita de um saber educativo específico e amparado no conhecimento científico.

O saber educativo consiste na mobilização de todos esses saberes em torno de cada situação educativa concreta no sentido da consecução do objectivo definidor da acção profissional - a aprendizagem do aluno. Desta mobilização reflectida e ajustada de saberes prévios (gestão de saber), resulta, por sua vez, a emergência de saber específico da profissão, que nasce do exercício da mesma e da dialéctica saberes/situações que o acto de ensinar envolve (produção de saber). (ROLDÃO, 1998, p.84).

Nesse sentido, o reconhecimento das peculiaridades da infância, tendo em vista que a instituição de Educação Infantil é concebida como espaço de educação e cuidado e a criança é entendida como sujeito histórico, torna-se imprescindível para a formação dos professores de educação infantil.

Destarte, é evidente a urgência de revisão dos cursos de Pedagogia, mas precisamos também de formação continuada que discuta a práxis. Roldão (2006, p.105) aposta na formação por imersão, capaz de "[...] assumir uma ruptura de paradigma nas lógicas de trabalho nas universidades e nas instituições de formação [...]”, porque acredita na transformação tanto da formação inicial quanto na continuada. Explica ainda que a formação por imersão é realizada nas instituições de educação infantil, em que os futuros professores são inseridos nos contextos de trabalho e as instituições se transformam em unidades de formação.

A proposta de formação por imersão poderia ocorrer nos estágios, se contemplada nos projetos dos cursos de Pedagogia, numa parceria com os professores das demais disciplinas e com as instituições de educação infantil.

A pesquisa realizada por Rosangela Aparecida Galdi da Silva (2011, p.142-144) descreve os pressupostos para a formação dos professores para a Educação Infantil, primando pelo atendimento das necessidades formativas dos profissionais que atuam com as crianças pequenas, como "[...] conhecimento dos fins educativos, conhecimento de si mesmo, conhecimento do conteúdo disciplinar, conhecimento científicopedagógico, conhecimento do currículo, conhecimento pedagógico em geral, conhecimento do aluno e das suas características, conhecimento dos contextos." Tais pressupostos poderiam ser considerados na organização dos cursos de Pedagogia, uma vez que, diante de tudo o que foi exposto, com base nas pesquisas localizadas, o 
currículo pensado e vivido do Curso de Pedagogia não vem contribuindo para a constituição do professor da educação infantil, nem sequer para o desempenho de sua função: cuidar-educar as crianças pequenas.

Como decorrência dessas considerações, sugerimos a realização de projetos de formação inicial e continuada, cuja intencionalidade seja uma formação integrada à futura prática profissional. Trata-se de ação colaborativa entre os órgãos municipais de educação, as universidades e as instituições de Educação Infantil, para a realização de formação dos profissionais de Educação Infantil, porque, assim como Guimarães et al. (2009, p.2654), apostamos na “[...] invenção de uma profissão, a do profissional de Educação Infantil, a partir da intencionalidade de seus formadores que perpassa a sua atuação e abrange as pesquisas científicas e as políticas públicas.”

\title{
TRAINING OF TEACHERS FOR THE EARLY CHILDHOOD EDUCATION IN THE PEDAGOGY COURSE: REFLECTIONS FROM THE ANALYSIS OF SCIENTIFIC PRODUCTION (2002-2013)
}

\begin{abstract}
This article discusses the issue of teacher training for early childhood education and summarizes trends in Brazilian theses and dissertations about the training in the pedagogy course. Considering this objective, we contextualize briefly the history of the training of early childhood education teachers to identify which issues are challenging. The bibliographic mapping of Brazilian academic research focused on initial teacher training for early education in the pedagogy course, published between 2002 and 2013, was held in the database in the Brazilian Digital Library of Theses and Dissertations (BDTD). This survey identified aspects that may be constituted as contributions to public policies and trainers of early childhood teachers. The analysis revealed the precariousness of the training for teachers of early childhood education. The studies suggest that the pedagogy course does not provide the knowledge necessary for teachers to choose appropriate referrals to education of young children to perform their duty to care-educate. Similarly, it compromises the invention of a profession: the Early Childhood professional. This scenario calls for urgent efforts for integrated training for future professional practice through projects that combine initial and continuing training.
\end{abstract}

KEYWORDS: Childhood Education. Public policy. Pedagogy course. Training. Supervision.

\section{REFERÊNCIAS}

ALMADA, F. de A. C. de. A formação do professor de educação infantil no curso de pedagogia de um centro universitário: uma análise a partir da teoria históricocultural. 2011. 171f. Tese (Doutorado em Educação) - Faculdade de Filosofia e Ciências, Universidade Estadual Paulista, Marília, 2011. 
BRASIL. Lei n.9.394, de 20 de dezembro de 1996. Lei de Diretrizes e Bases da Educação Nacional. Estabelece as diretrizes e bases da educação nacional. Diário Oficial da União: República Federativa do Brasil, Brasília, DF, 20 dez. 1996.

Disponível em: <http://planalto.gov.vr/ccivil_03/Leis/L9394.htm > Acesso em: 14 mar. 2009.

. Lei n.8.069, de 13 de julho de 1990. Estatuto da Criança e do Adolescente. Dispõe sobre o Estatuto da Criança e do Adolescente e dá outras providências. Diário Oficial da União: República Federativa do Brasil, Brasília, DF, 13 jul. 1990. Disponível em: <http://www3.dataprev.gov.br/SISLEX/paginas/33/1990/8069.htm> Acesso em: 14 mar. 2009.

BRASIL. Ministério da Educação e Cultura. Por uma política de formação do profissional de Educação Infantil. Brasília: MEC/SEF/DPE/COEDI, 1994.

BRASIL. Constituição (1988). Constituição da República Federativa do Brasil: promulgada em 5 de outubro de 1988. Organização do texto por Juarez de Oliveira. 4.ed. São Paulo: Saraiva, 1990. (Série Legislação Brasileira).

CAMPOS, M. M. Educar e cuidar: questões sobre o perfil do profissional de Educação Infantil. In: BRASIL. Ministério da Educação e Cultura. Por uma política de formação do profissional de Educação Infantil. Brasília: MEC/SEF/DPE/COEDI, 1994, p.32-42.

CHRUN, S. G. de L. Formação de professores da Educação Infantil no Paraná: políticas e legislações educacionais (1961-1996). 2009. 90f. Dissertação (Mestrado em Educação) - Faculdade de Filosofia e Ciências, Universidade Estadual Paulista, Marília, 2009.

CONSELHO NACIONAL DE EDUCAÇÃO. Revisão das Diretrizes Curriculares Nacionais para a Educação Infantil. Parecer CNE/CEB n.20, de 2009, de 11 de novembro de 2009. Diário Oficial da União: Republica Federativa do Brasil, Brasília, DF, 09 dez. 2009. Disponível em:

$<$ http://portal.mec.gov.br/index.php?option=com_content\&view=article\&id=12745:ceb2009\&catid=323:orgaos-vinculados >. Acesso em: 28 mar. 2010.

Institui as Diretrizes Curriculares Nacionais para o curso de Graduação em Pedagogia, licenciatura. Resolução CNE/CP n.1, de 15 de maio de 2006. Diário Oficial da União: Republica Federativa do Brasil, Brasília, DF, 16 maio 2006. Disponível em: < http://portal.mec.gov.br/cne/arquivos/pdf/rcp01_06.pdf>. Acesso em: 01 ago. 2010.

. Institui Diretrizes Curriculares Nacionais para o Curso de Pedagogia. Parecer CNE/CP n.5, de 13 de dezembro 2005. Diário Oficial da União: Republica Federativa do Brasil, Brasília, DF, 13 dez. 2005. Disponível em: <http://portal.mec.gov.br/cne/arquivos/pdf/pcp05_05.pdf>. Acesso em: 14 mar. 2009.

Institui Diretrizes Curriculares Nacionais para a formação de professores da Educação Básica, em nível superior, curso de licenciatura, de graduação plena. Resolução CNE/CP n.1, de 18 de fevereiro de 2002. Diário Oficial da União: 
Republica Federativa do Brasil, Brasília, DF, 18 fev. 2002. Disponível em:

<http://portal.mec.gov.br/seesp/arquivos/pdf/res1_2.pdf>. Acesso em: 14 mar. 2009.

COSTA, R. T. da. A habilitação em Educação Infantil no curso de Pedagogia da PUC-SP: um estudo de caso. 2005. 193f. Tese (Doutorado em Educação) - Pontifícia Universidade Católica, São Paulo, 2005.

DALRI, J. C. Contribuições do curso de Pedagogia para atuação com crianças de 0 a 3 anos. 2007. 119f. Dissertação (Mestrado em Educação) - Universidade do Vale do Itajaí, Itajaí, 2007.

FEBRONIO, M. da P. G. Formação inicial de professores de educação infantil: que formação é essa? 2010. 136f. Dissertação (Mestrado em Educação) - Universidade Católica de Santos, Santos, 2010.

GATTI, B. A.; BARRETO, E. S. de S. Professores do Brasil: impasses e desafios. Brasília: UNESCO, 2009.

GUIMARÃES, C. M. et al. O que revelam os estudos brasileiros sobre as práticas de formação de professores para a educação infantil. In: CONGRESSO NACIONAL DE EDUCAÇÃO - EDUCERE e III ENCONTRO SUL BRASILEIRO DE PSICOPEDAGOGIA, 9., 2009, Curitiba. Anais... Paraná: PUC/PR, 2009. p.2643-2656.

IRGANG, S. R. P. Baús de saberes e de significações imaginárias: o lugar da infância na formação docente de três professoras egressas do curso de pedagogia. 2009. $137 \mathrm{f}$. Dissertação (Mestrado em Educação) - Universidade Federal de Santa Maria, Santa Maria, 2009.

LIBÂNEO, J. C. Diretrizes curriculares da pedagogia: imprecisões teóricas e concepção estreita da formação profissional de educadores. Educação \& Sociedade, Campinas, n.96, p.843-876, out. 2006. Disponível em: 〈http://www.cedes.unicamp.br〉. Acesso em: 23 dez. 2010.

OLIVEIRA, A. D. S. de. A formação em pedagogia para a docência na educação infantil: em busca do sentido da qualidade. 2007. 256f. Dissertação (Mestrado em Educação) - Faculdade de Educação, Universidade de Brasília, Brasília, 2007.

OSHIRO, K. A formação de professores para a infância em Campo Grande/MS: concepções e práticas de educadores após a Habilitação em Educação Infantil. 2010. 189f. Dissertação (Mestrado em Educação) - Universidade Católica Dom Bosco, Campo Grande, 2010.

RODRIGUES, V. M. A formação política do professor de educação infantil: entre a construção coletiva histórica e a regulamentação das competências do modelo neoliberal. 2003. 171f. Dissertação (Mestrado em Educação) - Universidade Estadual de Campinas, Campinas, 2003.

ROLDÃO, M. do C. Professores para quê? para uma reconceptualização da formação de profissionais de ensino. Revista Discursos, Lisboa, n.2, p.95-120, 2006. 
Que é ser professor hoje? - a profissionalidade docente revisitada. Revista da ESES, v.9, p.79-87, 1998. Nova Série.

SAVIANI, D. História da formação docente no Brasil: três momentos decisivos. Revista do Centro de Educação, Santa Maria, v.30, n.2, p.11-26, 2005.

SILVA, Anamaria Santana da. A professora de educação infantil e sua formação universitária. 2003. 223f. Tese (Doutorado em Educação) - Faculdade de Educação, Universidade de Campinas, Campinas, 2003.

SILVA, Jória Pessoa de Oliveira. O professor de educação infantil e a importância da formação inicial na prática pedagógica. 2002. 94f. Dissertação (Mestrado em Educação) - Universidade Católica Dom Bosco, Campo Grande, 2002.

SILVA, Rosangela Aparecida Galdi da. Formação de professores de Educação Infantil: perspectivas para projetos de formação e de supervisão. 2011. 275f. Dissertação (Mestrado em Educação) - Faculdade de Ciências e Tecnologia, Universidade Estadual Paulista, Presidente Prudente, 2011.

SILVEIRA, T. A. T. M. A educação infantil no curso de pedagogia da FE/UFG sob a perspectiva discente. 2007. 221f. Dissertação (Mestrado em Educação) - Faculdade de Educação, Universidade Federal de Goiás, Goiânia, 2007.

VOLPI, N. Contribuições de teses e dissertações para a formação do professor da educação infantil. 2006. 123f. Dissertação (Mestrado em Educação) - Pontifícia Universidade Católica do Paraná, Curitiba, 2006. 